\title{
Guns Versus Butter Tradeoff: The Theory of Defense Quality Factor
}

\author{
Emre Dikici
}

\begin{abstract}
The aim of this paper is to reach sound recommendations for a developing country with regards to optimally balancing defense and welfare expenditures for maximum defense effectiveness in this age of increasing budgetary pressures over defense.

The paper analyzes the literature concerning the balance between defense spending and the sum of education and health expenditures, addressed as welfare expenditures in this study for simplification purposes. Then, the mechanism of how a qualified human capital affects the quality of defense as a public good is questioned, which lead the study to the theorization of "defense quality factor". This paper introduces "defense quality factor" to the literature of defense economics, defined as the multiplier that converts defense resources into defense effectiveness. The functioning of defense quality factor is demonstrated on a theoretical five-term budget allocation model. Finally, the paper concludes with recommendations for the optimal guns versus butter tradeoff decision for a developing country, in consideration of the defense quality factor theory.
\end{abstract}

Index Terms-Defense spending, defense quality factor, defense welfare tradeoff, guns versus butter tradeoff.

\section{INTRODUCTION}

The allocation of financial resources among budgetary items is one of the most concrete indicators of the policies followed and preferences set by governments. What history shows us is that there emerges considerable rise in defense expenditures before great conflicts, while defense spending tends to decline in times of peace, accompanied by a rise in allocations for public investment and social state expenditures having been neglected during times of war or crisis [1]. While welfare expenditure is exposed to cyclical fragility depending on the stability of states' social policies, government reshuffles, and political preferences, defense expenditure mostly relies on internal, regional and global security environment rather than domestic factors and takes more time for dramatic shifts. Moreover, studies in this context reveal that welfare and defense expenditures literally present competing budgetary priorities for getting a bigger slice out of the cake to the detriment of the other [2]. This study focuses on the relationship between defense and welfare expenditures as well as linking governments' preferences to their relations with international actors, thus adding the dimension of international relations and security strategies to this very field which is conventionally regarded

Manuscript received November 11, 2013; revised January 13, 2014.

Emre Dikici is with the Turkish Army War College, Istanbul, Turkey (e-mail: emredkc@gmail.com). in the context of defense economics.

\section{DeFENSE AND Welfare EXPENDITURE}

Defense expenditures can be defined as public expenditures allocated for security and defense needs that are basically of military nature. There is no consensus among nations over which spending items to be accepted as defense expenditures. The manipulative efforts of governments about the declared budget figures, the lack of transparency with regards to defense spending due to various concerns, the bad-keeping of records and the failure at producing healthy data due to deficiency of technical infrastructure or lack of sensitivity are the main factors that forbid the accurate reflecting and assessment of defense spending [3].

The analysis of overlapping figures of the defense spending definition made by globally recognized bodies such as International Money Fund (IMF), United Nations (UN) and North Atlantic Treaty Organization (NATO) yields the payments made to the military and civilian personnel of armed forces, military health, education, infrastructure, acquisition, operations, maintenance and sustainment, research and development as well as military aid to other countries, civil defense/protection, border security and the expenses for official paramilitary organizations as the generally accepted defense expenditures [4].

Welfare expenditures, on the other side, are usually regarded in the context of social state and consist of education and health expenditures, social security expenditures, expenditures for supporting the children and the family, transfer payments and the expenditures made in the context of public support for the low-income mass against the unfair distribution of income [5]. Given that social security expenditures are somehow stable over time due to their nature of being the extension of governments' continuous commitments, the variance of these expenditures should be attributed to the aging population and the increasing number of veterans rather than cyclical preferences of governments [6]. For instance, in United States, social security expenditures have been rising due to the ongoing retirement of the so-called baby-boom generation born in the years following World War II when there had been an extraordinary rise in birth rates [7]. The welfare expenditures relevant in the context of defense-welfare tradeoff, on the other side, are education and health expenditures that are more flexible regarding cyclical variances due to government policies. In an econometric analysis carried out for Turkey, a significant negative correlation proving a clear tradeoff between defense and welfare expenditures (taken as the sum of health and 
education expenditures) had been revealed [8]. In line with the mentioned study, the welfare expenditures basic to preference will be presumed as the sum of public education and health expenditures in this paper.

\section{Defense-Welfare NeXus and Guns Versus Butter TRADEOFF}

Guns versus butter tradeoff reflects the defense-welfare model of production possibility frontier which is a basic macroeconomic phenomenon. Production possibility frontier, utilizing the simplificative logic of classical macroeconomics, is a graphic displaying that a country with the possibility of producing only two types of items, has to portion out all of its resources among these two items in order to ensure an optimal balance. It also shows that inefficiency rises due to the rule of diminishing returns coming into effect towards the point where solely either one of two items is produced [9]. When guns versus butter tradeoff is modeled using production possibility curve, one of the producible items becomes guns for defense expenditures, as the other being butter for welfare expenditures.

Robert Gilpin carries the discussion of guns versus butter tradeoff and production possibility frontier to a very different platform of macroeconomics; the indifference curve [10]. According to Gilpin, an increase in the resources of a nation shifts the production possibility frontier outwards while the change in the relative prices of two items (guns for defense and butter for welfare) changes the form of the indifference curve, in other words, how the nation allocates its resources among two items. Econometric and statistical studies verify that defense and welfare budgets are rival figures [2], however it is not possible to define a universal optimal balance among two.

Most of the studies in the field of defense economics with regards to defense-welfare tradeoff basically focus on the effects of defense and welfare expenditures. Defense expenditures influence economic performance through three channels. Ram classifies them as demand side, supply side and security effects [11]. The fact that each unit of defense expenditure brings an alternative cost due to the abandoned investment opportunities in the framework of scarcity theory generates supply side effects similar to the guns versus butter tradeoff paradigm. Economists asserting that defense expenditures influence economy through the channel of demand fundamentally ground their points on the Keynesian multiplier effect [12]. Namely, in an economy which is not running at full employment of resources, a rise in defense spending causes a rise in aggregate demand. Since the resources are scarce, the rise in aggregate demand causes a decrease in unemployment through the rise of capital utilization. Therefore, an increase in defense spending results in economic growth. The supporters of this view ignore the supply side effects considering the assumption that there are always idle resources in a given economy. Security effects channel, the third channel explaining the nexus of defense spending and economic growth, refers to the economic value of national defense service yielded by defense expenditures which is a public good in the sense of economics [13]. A convenient and encouraging setting for private investment is only achievable in a country where a secure environment is ensured by the government. On the other side, since there is almost general consensus in the literature over the positive effects of human capital creation via public investments in education and health on economic performance, the mechanism of this effect is considerably axiomatic.

\section{DEFENSE SPENDING AND THE RELATIONS WITH GLOBAL/REGIONAL ACTORS}

It was stated in the second part of the study in the context of indifference curve that a shift in the relative prices of items representing defense and welfare would change the shape of both the production possibility frontier and the indifference curve. Gilpin asserts that this condition will generally result in a change in the foreign policy of the state as well [14]. In this part, the relationship between foreign policy and the defense preferences will be discussed in line with Gilpin's perspective, but by approaching to the causality he mentions from an opposite side.

It is possible to expect that the relations developed with global and regional actors by governments would influence defense expenditures via two channels. First one, similar with the security effects regarded as the fundamental value of defense spending [12], is the investability effect provided by the deterrence cover achieved by joining global and regional defense alliances. Second one is the opportunity of economic development provided by allocating more resources for welfare through reducing security concerns by, again, joining alliances, thus reducing the need for a high defense budget. In fact, these two effects pursue nested mechanisms so that they cannot be clearly distinguished from one another. However, this deterrence based on diplomacy rather than military power can be deceptive. For instance, avoidance of a NATO country from acquiring expensive high altitude air and missile defense systems with the expectation of enjoying NATO air and missile defense capabilities would be a decision of high risk since there is no precedent joint defense of an attacked NATO country in a high-scale conventional warfare in the context of NATO Article-5 and the commitments in this respect have not been tested under real circumstances yet. In this case, the dividend created via preferring the economic benefit of avoiding acquisition over the security benefit of acquisition can be defined as security risk dividend. Security risk dividend occurs as a result of not making the security investment that would develop measures against a threat and taking the risk of that threat with presuming/expecting that the risk will not happen. Then, security risk dividend can be calculated by subtracting the security benefit of making the security investment from the opportunity cost of making the avoided security investment. The security risk dividend concept which is defined in this paper for the first time will be discussed in detail in another paper as introduction of the term to the literature of defense economics.

It is a frequent situation that some countries, thanks to the defense alliances they develop, acquire the security and deterrance needs that they can not satisfy by themselves. For instance, Taiwan is able to shift the savings from defense resources for more productive purposes by pulling down its 
security concerns stemming from China, which she cannot absorb with its own resources, to a more reasonable level [15] However, enjoying the benefits of a defense alliance with another country without sharing the costs is not a sustainable position. Let us remind at this point the quote from the former US Secretary of Defense Mr. Gates that "Future U.S. political leaders ... may not consider the return on America's investment in NATO worth the cost" [16] in view of the belief that operational and financial contributions by NATO-member European countries for NATO operations, chiefly the ISAF, are unacceptably low. Nevertheless, countries often leave the responsibility of fulfilling some defense functions to certain organizations or countries nowadays. For instance, the air defense of four Baltic countries (Iceland, Finland, Sweden and Norway) is being undertaken by NATO capabilities since 2004 as part of NATO Air Policing [17]. Besides, an acquisition consolidation trend led by Britain and France draws attention. We see in this context that countries tend to unite or collectivize some capabilities which serve the same purposes yet they used to own individually before, and we assess that this trend will increasingly continue in the short and middle term. This concept has been stated as "Smart Defense" by NATO Secretary General and has been introduced as an optimization-based defense planning solution in response to decreasing European military spending and the defense gaps of NATO-member European countries. The concept can be characterized by sustainment by pooling and utilization by alliance when needed of the capabilities that countries do not constantly need or cannot maintain due to exorbitant expenses. An example for this is the Heavy Airlift Wing composed of three C-17 aircrafts located in Papa Air Base, Hungary, and financed by a 12-country consortium [18]. Similar saving efforts are also shown in the framework of bilateral or triple alliances. For instance, Belgium and France have agreed upon using common infrastructure and facilities for training military pilots [19].

We shall hereby mention Japan and Germany, who first achieved a great economic power and then an unignorable military capacity after coming out defeated from World War-II. Both countries defined as "trading states" by Robert Gilpin with reference to Rosecrance have achieved their economic development under the U.S. defense umbrella and have utilized their sophisticated technology and qualified manpower for creating a serious defense industry afterwards [10].

Immanuel Wallerstein asserts that while dominant Powers in international political order focus on defense industry and military power, the actors in position of their rivals and successors attach priority to economic progress [20]. Indeed, analysis of both the examples of Germany and Japan as well as today's popular case of China reveals that defense capabilities are kept at minimal deterrent level necessary for maintaining the continuity of economic progress and that leaps in the field of military follow the maturation of economic growth until becoming a global economic power. Organski's Power Transition Theory assesses a nation's rise in a manner that would trigger a globally dominant power's concern of losing leadership as a distinct indicator of war [21]. In fact, both the world wars broke out as a result of
German power in the context of Anglo-German rivalry. Similarly, Thucydides tells Athens's rise and Sparta's disquietude of this fact as the mainspring of the war in his 2500-year-old famous History of the Peloponnesian War [22]. The main point to take into account here is the fact that the primary factor for rising powers to be perceived as a threat by dominant powers is not solely economic or political reflections but generally their military capabilities and their (potential of) use of them. We can therefore conclude that the smart attitude for rising powers is first focusing on economic progress without agitating dominant powers as far as possible, then fortifying their military power via the resources provided by this economic capacity, and while doing this, staying away from devastative risks of war that would endanger all their historical gaining.

Governments have to provide domestic peace and political stability to safeguard their national security. A country that has not provided social peace and that hosts deep political splits as well as social fractures would feel less secure relative to a country with equivalent military and economic power. Therefore, another condition for establishing national security is political and social stability. The main tool for building up such stability is public policy, and the chief instrument for implementing public policy is the public finance. The state can provide stability with the expenditure preferences. Public finance undertakes this function by removing inequality in income distribution, providing minimally sufficient living standards for citizens, providing convenient infrastructure for development of human capital and raising educated and healthy generations (human capital). The allocation preference of scarce resources is the key element that reflects governments' ability ingenuity of simultaneously and sufficiently satisfying all the dimensions of national security. In this case, the relation of guns versus butter tradeoff with national security is not only subject to economic but also political dimensions.

\section{A THEORY: DeFENSE QUALITy FACTOR}

\section{A. The Notion of Defense Quality}

Before presenting a model suggestion at the end of the study, we find it useful to theorize the basic assumptions the model is built upon. First, considering the fact that military power is directly proportional to military spending, there needs to be a soft factor for converting defense capacity to defense quality. This factor that we name as Defense Quality Factor $(D Q F)$, can be defined as the multiplier that reflects the effectiveness difference between two countries' armed forces making the same defense expenditure or having the same equipment at same quantities. Nominately, a country's defense effectiveness $(D E)$ can be accepted equal to the multiplication of the aggregate value of resources allocated for defense (defense resources) and DQF which can be characterized more with the quality of manpower, as well as the technology, experience and moral values owned:

$$
D E=\text { Defense Resources } \times D Q F
$$

In this equation, defense resources define all types of 
resources that can be provided through financial means. For instance, physical potential such as soldier count, number of vehicles, arms and equipment, ammunition stockage can be quantified as a country's defense resources. Moreover, liquid resources, namely the budget and funds allocated for defense should be added on. As is evident from this definition, defense resources are directly proportionate to the aggregate cumulative defense budget.

As we briefly mentioned before, DQF, on the other side, is a multiplier that reflects the soft factors such as manpower quality, moral values, and the capacity to generate and use technology. DQF refers to the potential of high or low-efficient utilization of available resources by being greater or less than an index value of " 1 ".

The defense effectiveness as being the multiplication of these two values comes out as a resultant value that can be used for comparing countries' military capacities, similar to the relative combat power value used in military jargon.

When this equation is analyzed, it can be noticed that one of the two multipliers resulting in the composite value of defense effectiveness can be increased through defense expenditures (defense resources) while the other can be done so by welfare expenditures (defense quality factor). The reason for particularly refraining from the use of term "directly proportionate" is that the welfare investment can be a high-yield domain where even a logarithmic relation can occur between DQF and welfare expenditures. Referring back to the acknowledgement of defense and welfare spending as rival budget figures, that a rise on one side (multiplier) would result in a fall on the other (multiplicand) renders the question of how the product will be affected, the principal unknown of the equation. Essentially, the solution of defense-welfare equilibria argument lies within this point.

Let us try solving this problem in the framework of one unit of budget transferred to welfare expenditures renouncing defense expenditures. This one unit transfer would result in one unit of fall in the variable of defense resources. Provided the rise at DQF caused by this transfer happens to be the same in ratio, this would not affect the product, namely the defense effectiveness. The preference at this point displays the same character as the preference between two items having a 450 indifference curve which is not concave or convex. Whereas, the investment on human capital, besides positively influencing manpower quality, technology development and utilization capacity and moral subjects, also results in the domestic production capability of defense items, reduction of production costs, and a fall in the number of soldiers needed, thus positively influences both the factors. Then, the effect of this transfer would be in a direction to increase the value of the product, namely the defense effectiveness. However, in just the same way as the rule of diminishing returns, as the defense expenditures go below the level necessary for minimum deterrence, defense effectiveness begins to fall. Therefore, a defense spending level which should be autonomously maintained is referable.

\section{B. An Explanatory Fictional Model}

In this part of the study, we will try to draw a conclusion about defense-welfare equilibria by examining the previously theorized DQF's effects over a model. To that end, we will present the defense effectiveness values as results of various defense-welfare resource allocation ratios in five consecutive terms for a country which has an initial GDP of one trillion. The assumptions to be used in this model are that;

1) The sum of defense and welfare expenditures is fixed at $10 \%$ of the country's GDP,

2) A rise in welfare expenditures result in a rise in the DQF on the subsequent term, and,

3) The DQF and defense effectiveness (DE) values of the first term are regarded as index values and taken as " 1 ".

Also, for simplification purposes, already present welfare and defense assets (i.e. active schools, hospitals, arms and equipment in inventory) are not quantified and are excluded in the model. Since the impact of the preferences is questioned, the financial resources subject to cyclic budgetary tradeoff are taken into account. The monetary values given in the Table I below are normalized to first term current prices, that is, net of inflation.

TABLE I: FIVE-TERM DEFENSE-WELFARE ALlocAtion MODEL

\begin{tabular}{|l|l|l|l|l|l|l|l|}
\hline Term & $\begin{array}{l}\text { GDP } \\
(\text { USD })\end{array}$ & $\begin{array}{l}\text { Def. } \\
(\%)\end{array}$ & $\begin{array}{l}\text { Def. } \\
(\text { real })\end{array}$ & $\begin{array}{l}\text { Wlf. } \\
(\%)\end{array}$ & $\begin{array}{l}\text { Wlf. } \\
(\text { real })\end{array}$ & DQF & DE \\
\hline 1 & $1 \mathrm{TN}$ & 2 & $20 \mathrm{BN}$ & 8 & $80 \mathrm{BN}$ & 1 & 1 \\
\hline 2 & $1,3 \mathrm{TN}$ & 2 & $26 \mathrm{BN}$ & 8 & $104 \mathrm{BN}$ & 1,2 & 1,56 \\
\hline 3 & $1,5 \mathrm{TN}$ & 1,8 & $\begin{array}{l}27,5 \\
\mathrm{BN}\end{array}$ & 8,2 & $122,5 \mathrm{BN}$ & 1,4 & 1,93 \\
\hline 4 & $1,8 \mathrm{TN}$ & 1,5 & $\begin{array}{l}27,5 \\
\mathrm{BN}\end{array}$ & 8,5 & $153 \mathrm{BN}$ & 1,7 & 2,34 \\
\hline 5 & $2 \mathrm{TN}$ & 1,5 & $30 \mathrm{BN}$ & 8,5 & $170 \mathrm{BN}$ & 2 & 3 \\
\hline
\end{tabular}

Def. $(\%)=$ Defense expenditures as percent of GDP,

Def. (real) = Real value of defense expenditures in constant US dollars, Wlf. $(\%)=$ Welfare expenditures as percent of GDP,

Wlf. $($ real $)=$ Real value of welfare expenditures in constant US dollars, $\mathrm{DQF}=$ Defense quality factor,

$\mathrm{DE}=$ Defense effectiveness (over index value of "1").

Now, in the light of DQF theory, we will discuss how defense-welfare preferences results in. Above table does not reflect a five-year model, but the values taken from five different crosscuts from a middle-term program that spans over a $10-15$ years period.

The first thing noticeable in the model is the fall in defense expenditures as a percentage of GDP while defense spending in real dollars rises. As the GDP doubles at the end of the program, a $25 \%$ fall in defense expenditures as a percentage of GDP has occurred, whereas real defense spending has risen by $50 \%$ due to the GDP growth.

The second interesting point is that, defense quality factor doubles while defense effectiveness triples at the end of the program. The results that defense effectiveness rises by $200 \%$ while defense spending as percentage of GDP falls and real defense spending rises by only $50 \%$ set forth a remarkable conclusion given the validity of the assumptions the model grounds on.

The numbers given in the table are, of course, fictional. However, they are built in a logical integrity in consideration of the assumptions theorized under the title of defense quality factor. So, is it possible for a developing country to launch a similar allocation model and incorporate it to national development programs? There are several issues the statesmen have to decide for this. For instance:

1) What are the national objectives of the country in regional and global scale? What is the minimum level to 
be reached in each national power element categories (i.e. military power, economic power, etc.) for providing them?

2) What is the lowest necessary level of deterrence for the country within the program period considering the current and potential regional and global developments, threats and risks?

3) What are the irrecusable capabilities to own for ensuring the minimum necessary level of deterrence?

4) What is the projection concerning the contribution of national defense industry in the acquisition of defense items and services as well as the planning with regard to this?

5) What will be the market share of the national defense industry in global defense market?

6) How will the transitivity of technology, knowledge and qualified manpower between defense industry and productive (civilian) sectors be?

A program to serve as basis for budget planning with regards to defense-welfare preference can be built only after answering the above questions. Certainly, this program should have the flexibility areas to enable responding to unforeseen developments; moreover should it provide feedback for the program monitoring the quantifiable impacts of the policies adopted sensitively and with neutrality.

\section{CONCLUSION}

As discussed in the previous part, military, international, economic, political and social systems stand out as the rings that compose the chain of national security system. Military subsystem should be regarded as a short and middle-term security instrument as it essentially provides deterrence against the current threat environment. International subsystem acts as the weakest ring of the national security chain due to its slippery and fragile structure, inherent unreliability as well as the unpredictability and uncontrollability of the decision makers. Political and social subsystem is the structure to constitute the spirit of national security system which can be defined as the software of the state mechanism. The distinctive feature of this structure as opposed to many other immaterial structures is its ability to be fortified through material capabilities. Lastly, economic subsystem is essentially the structure that feeds the ingredients of the national security compound and comprises the resources and the control mechanisms of the material inputs.

With reference to this analytical approach, we conclude that countries should fortify the political and social structure comprising the core of all dimensions of national power particularly through economic structure that feeds all subsystems in order to warrant their national security in the long run. Yet, the making of a deterrent military power can be possible principally through the continuous and efficient interaction of two input groups being the economic and human resources. Welfare policies and investments devoted to human capital development are essential for ensuring the technological, industrial and commercial competitiveness needed for economic power in the long run. Likewise, the health of political and social structure can be ensured and maintained through the same policies and investments. Within this scope, we conclude that welfare policies and investments should be the privileged and preferred investment domain as they provide basis for the other dimensions of national security.

The defense quality factor theory that we put forth in consideration of the thought that defense effectiveness is related to information superiority, technological superiority and human capital quality as well as the budget allocation table modeled based on that theory are in a sense the summary of this study. For the case of a developing country, the defense expenditures should be kept at a level so as to provide the minimum necessary level of deterrence and to enable the R\&D and conceptual design activities that foster the nationalization of defense industry until the economic progress and qualified human capital formation is matured. It should be avoided to respond to evolving risks and threats in a way that would overbalance the defense expenditures unless they endanger the strategic vision. It should be aimed to prioritize welfare expenditures, particularly the education in order to reach a human capital formation, national technology and defense industry that would create a multiplier effect over defense resources. For achieving the national objectives, a national power projection following the consecutive levels of reactive regional deterrence, proactive regional deterrence, active regional power and active global power should be set forth and an accordingly budget, resource and effort allocation should be planned.

In brief, the conclusion reached in the context of defense-welfare argument, using the Keynesian simplification in the beginning of this paper, is that a country capable of producing butter and guns only should prefer to produce butter which has a greater marginal utility at an assumed equilibrium point for providing the manpower that can produce and use higher quality and more effective guns in the future. In fact, the Turkish saying of "Let people live so the state would live" summarizes the findings of this paper by emphasizing the importance of human capital formation for the continuity of the state.

\section{REFERENCES}

[1] J. M. Treddenick, "Defense and economics: some issues for the post-cold war world," Canadian Journal of Economics, vol. 29, no. 2, pp. 644-648, April 1996.

[2] A. Panagariya and H. Shibata, "Defense and welfare under rivalry," International Economic Review, vol. 44, no. 4, pp. 951-969, November 2000 .

[3] E. Tekelioğlu. (2008). Defense expenditure and economic growth Empirical study on Case of Turkey. MBA Professional Report. Graduate School of Business \& Public Policy, Naval Postgraduate School, Monterey (CA), USA. [Online]. Available: http://handle.dtic.mil/100.2/ADA483487

[4] M. Brzoska, "World military expenditures," in Handbook of Defense Economics, K. Hartley, and T. Sandler, Eds. Amsterdam: Elsevier, vol. 1, pp. $45-67,1995$.

[5] N. Rudra, "Openness, welfare spending, and inequality in the developing world," International Studies Quarterly, Malden (MA), USA, vol. 48, pp. 683-709, 2004.

[6] V. Meier and M. Werding, "Ageing and the welfare state: securing sustainability," Oxford Review of Economic Policy, vol. 26, no. 4, pp. 655-673, December 2010.

[7] G. W. BUSH. (2006). State of the Union. [Online]. Available: http://www.washingtonpost.com/wp-dyn/content/article/2006/01/31/ AR2006013101468.html 
[8] E. Dikici and Y. İduğ, "Defense expenditures and economic growth nexus: the case of turkey," Unpublished MBA Professional Report, Graduate School of Business \& Public Policy, Naval Postgraduate School, Monterey (CA), USA, 2011.

[9] İ. Parasiz, iktisadın $A B C$ 'si, Bursa: Ezgi Kitabevi, 2005.

[10] R. Gilpin, Global Political Economy: Understanding the International Economic Order, New Jersey: Princeton University Press, 2011.

[11] R. Ram, "Conceptual linkages between defense spending and economic growth: a selective review," in Defense Spending and Economic Growth, J. E. Payne, and A. P. Sahu, Eds. Boulder: Westview, 1993, pp. 19-39.

[12] P. Yakovlev, "Arms trade, military spending, and economic growth," Defence and Peace Economics, vol. 18, no. 4, pp. 317-338, June 2007.

[13] E. B. Kapstein, The Political Economy of National Security: A Global Perspective, Columbia, SC: University of South Carolina Press, 1992.

[14] R. Gilpin, War and Change in World Politics, New York: Cambridge University Press, 1981.

[15] M. Devore and L. Jones, "International Dynamics of U.S. National Defense Acquisition and Budgetary Policy," in Proc. the 9th Annual Acquisition Research Symposium, Naval Postgraduate School, Monterey (CA), USA, 2012, pp. 113-137.

[16] R. Burns. (Dec. 09, 2012). Gates blasts NATO, questions future of alliance. [Online]. Available: http://www.washingtontimes.com/news/2011/jun/10/gates-blasts-nato -questions-future-alliance/?page=all, Jun. 10, 2011

[17] (2012). Fighter jets secure airspace of the Baltic countries. [Online]. Available: http://www.nato.int/cps/en/natolive/news_85569.htm
[18] C. F. Schlegel, "The sovereign debt crisis: an opportunity for NATO reform," USAWC Strategy Research Project, United States Army War College, (PA), USA, 2012.

[19] A. F. Rasmussen, "Smart defence greater security for less money by working together," Hampton Roads International Security Quarterly Online, vol. 11, no. 2, April 2011.

[20] I. Wallerstein, "Amerikan Gücünün Gerileyişi (The Decline of American Power: The U.S. in a Chaotic World)," Istanbul: Metis Yayınları, in Turkish, 2003.

[21] S. Chan, "China, the U.S. and the power transition theory: a critique," The China Journal, no. 60, pp. 164-166, July 2008.

[22] R. B. Strassler, The Landmark Thuycydides: A Comprehensive Guide to the Peleponesian War, New York: The Free Press, 1998.

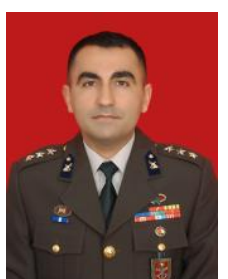

Emre Dikici was born in Hatay, Turkey in 1981. He hold a MBA degree from Naval Postgraduate School in California, USA, 2011 and a B.S. degree at systems engineering from Turkish Military Academy in Ankara, Turkey, 2003. His major fields of study are defense resources planning and defense transformation. He currently serves as an Army Captain at Turkish Army War College in Istanbul, Turkey. His previous service includes command and staff positions in various army units in Turkey and Kosovo as well as foreign training and education in the USA. His current research focuses on defense transformation and army modernization. 